\title{
A Study of Metacommunication Signals in the Initiation of Pretend Play of 3-6 year-old Children
}

\author{
Hongzhi Long ${ }^{1}$, Mengqi Wei ${ }^{2}$ \\ ${ }^{1}$ Research Center for the Educational Development of Minorities, College of Education, Northwest Normal University, Lanzhou, China \\ ${ }^{2}$ College of Educational Science, Hengyang Normal University, Hengyang, China
}

Email address:

453049639@qq.com (Hongzhi Long),1070044154@qq.com (Mengqi Wei)

\section{To cite this article:}

Hongzhi Long, Mengqi Wei. A Study of Metacommunication Signals in the Initiation of Pretend Play of 3-6 year-old Children. International Journal of Psychological and Brain Sciences. Vol. 4, No. 5, 2019, pp. 50-55. doi: 10.11648/j.ijpbs.20190405.11

Received: September 22, 2019; Accepted: October 28, 2019; Published: December 6, 2019

\begin{abstract}
Pretend play is the most typical play among children aged 3-6 years old, the initiation of which needs children's matecommunication ability. In turn, the temecommunication ability of children can be enhanced and strengthened during the play. And thus the topic of how children initiate matecommunication signals in the pretend play is worthy to research. Using observation as research method, the researchers analyzed the metacommunication signals in the initiation of pretend play of 60 children aged 3-6. The results are as follows: (1) the metacommunication signals used by children aged 3-6 on pretend play show a tendency of transition from non-verbal signals to verbal signals with the increase of age. (2) Metacommunication signals used in regional activities show a feature of borrowing special materials and being limited by material exploring ability, and metacommunication signals used in life activities show a feature of using spontaneous physical actions. (3) The signals used by familiar peers are identifiable and changed frequently, and signals used by unfamiliar peers are repeatedly explained and are controlled. Some suggestions are provided. Reachers propose responding suggestions for teachers in the kindergarten: (1) Properly place regional material (2) Support children's spontaneous communicative activities. (3) Promote the development of the psychological theory of children in junior class.
\end{abstract}

Keywords: Pretend Play, Metacommunication Signals, Children Aged 3-6

\section{Introduction}

Early in 1950s, anthropologist G. Bateson has put forward the concept of Metacommunication through the observation of monkey playing. [1] Metacommunication is a kind of abstract communication on the basis of symbolic level and both parties involving in the process of metacommunication need to identify and understand the real communicative intention of each other and make response. [2] And the achievement of this communicative intention relys on carrier---metacommunication. Metacommunication signals refer to verbal and non-verbal information indicting the special situation significance of certain behavior. [3] Due to its symbolic and fictional meaning, Pretend Play including abundant metacommunication sginals is the major game for children older than 2 year-old. Researches about metacommunication of children over the past were almost undertaken in the labour condition, in some degree effecting research efficiency. Using observation as research method, researchers analyze metacommunication signals and its features in the initiation of pretend play of 3-6 year-old children under the natural situation in order to make reference for teachers to understand children's behavior in the play and to encourage children's spontaneous communication.

\subsection{The Origin of Research}

\subsubsection{The Ability of Metacommunication is an Important Social Communication Ability}

G. Bateson pointed out that "There are signals representing other events in the play, and the progress of the play may be an important step in the process of communication." [1] Human beings need to communicate with the help of a certain carrier, that is, symbol. The signal used by children to initiate pretend play is an important symbol for communication between children, and also an important manifestation of their metacommunication ability. For the initiator of the play, the signal is endowed with certain meaning by children, who express their desire to play through the signal. The 
understanding of the partner to the signal means the understanding of the initiator's intention. If the partner cannot correctly understand the intention of the play implied by the signal, behavioral or verbal conflicts may occur. If the partner correctly understands the intention behind the signal, that is, he can correctly predict the intention of others, and then he can make appropriate responses to play the play. Children's social communication ability has been developed in the play.

\subsubsection{Metacommunication Research has Become the Focus of Play Research}

In the $1950 \mathrm{~s}$, anthropologist Bateson first put forward the concept of metacommunation through observing monkey play. He believed that metacommunication is about "the communication of communication" and used this concept to establish the metacommunication theory of play. His elaboration on metacommunication has aroused the continuous attention of subsequent researchers on metacommunication in children's play. [1] In the experimental situation, C. Garvey analyzed the metacommunication in children's pretend play from the perspective of language. [4] H. B. Schwartzman explained children's play and metacommuness in pretend play from the perspective of anthropology, paid attention to the influence of social situation of play on children's play, and initiated the naturalistic tendency of metacommuness research. [5] H. L. $\mathrm{N}$. Giffin described the exchange of "meaning" in pretend play from the perspective of early childhood culture in both experimental and natural contexts. [6]

In the past 30 years, researches on children's metacommunication in domestic and abroad have focused on the empirical researches on pretend metacommunication in play. Metacommunative behavior and strategies use of pretend play; metacommunication of preschool special children; metacommunication in make-believe play and children's language development; developmental characteristics of preschool children's metacommunication; Signals of metacommunication in the pretend play and influence factors of Signals of metacommunication. It can be seen that metacommunation research has become the focus of play research in recent 30 years and shows a continuous trend in time.

\subsubsection{Domestic Studies Have Paid Insufficient Attention to Children's Metacommunative Behaviors}

The author searched through the Internet and found that there were only four studies on metacommunication of children's play in China. Among these studies. There is only one empirical research. So, the space of metacommunication of play is nearly blank.

\subsection{Literature Review}

\subsubsection{Foreign Studies}

Research on metacommunication signals. Foreign researches on metacommunication signal started earlier, mainly from the following two aspects. On the one hand, it studied the signal content and gender difference. C. Garvey observed and analyzed the hypothetical play of 48 preschool children aged 2-5 years in a single experimental condition, and pointed out that although laughter is not a necessary sign of play, it is indeed a fairly common measurement factor. [4] Her theory of conversation divides play signals into 1. Changing your voice 2. Giggling while acting or speaking 3. Winking. [7] Boyd observed two scenarios of make-believe play in 33 preschool children aged 3-5 years under experimental conditions that controlled for age and gender. The study found that the frequency of metacommunication was not stable in the two scenarios, and the occurrence of metacommunication decreased with the development of cognition and psychological theory. [8] Sheng-hsi Lin observed the initiation and maintenance of dressing up play in 40 hours for 20 children aged 5-6 in two kindergartens in Taiwan under natural conditions, and found that the metacoracal signal of initiation was manifested on proposal. It is embodied in role assignment, object transition and situation (state) definition. The signal difference in role assignment shows that girls are more inclined to use verbal style, while boys are more inclined to use non-verbal style such as objects, posture and body movement, mainly focusing on the use of substitutes and the way or process of pretending the theme. In the transformation of objects, the signal differences are shown as girls' use of speech, boys' use of speech and non-speech. In context (state) definition, the signal difference is that girls use explicit proposals and boys use implicit proposals. In the process of game maintenance, girls are more likely to express their peers' opinions and seek explanations from others, while boys are more likely to express their own opinions that may be accepted by their peers. Girls are more likely to explain ongoing make-believe themes, characters, and plots to their peers to provide new ways of entering, while boys are more likely to provide information about what will be transformed, and they try to explain and limit what behavior can be accepted and achieve their goals. Girls are more likely to use pretend characters to create a sense of parallel or allied intimacy outside of play activities, while boys are more likely to emphasize the use of materials. [9]

On the other hand, some studies have studied the factors that affect children's metacommunative signals. The earliest research on factors can be traced back to H. B. Schwartzman, who believed that social situation affected children's metacommunative choice of pretending to play. [5] Further research by S. Reifel\&J. Yeatman indicated that children's metacompetitive communication is influenced by their materials in games, other people's thoughts, personal motivation and past experience. Metacommunative signals are related to social and physical situations: physical metacommunative signals are defined as materials, children's past experience with real objects, children's self-directed language or behavior caused by their own choices, and social metacommunative signals are defined as the previous language of peers or those behaviors pointing to peers. [10] Sheng-Hsi Lin continued the study on the physical situation and social situation of metacommunication signal that S. Reifel\&J. Yeatman did, 
she studied the factors influencing infant communication: she could be divided physical situation into material, time, space, and individual experience, the outside social situation is divided into class culture, social relations, social customs, social contract. [11]

Research on the relationship between metacommunication, peer and sociality. As the social situation factor that affects metacommunication, companion is closely related to metacommunication. The relationship between peers influences whether a play can be successfully initiated and maintained, which the researchers demonstrated by observing different conditions.

In addition, A. B. Doyle \& J. A. Connolly studied the relationship between explicit meta-communication and social adaptation, social recognition and social cognition of social pretend play. The research found that: ranking with peer liking and positive peer nomination, play setting and negotiation are two important indicators of peer popularity. [12]

\subsubsection{Domestic Research}

Research on metacommunation of pretend play started late in China, and there are few theoretical and empirical studies. one study is represented by Linhui $\mathrm{Li}$, she focused on the analysis of language characteristics of metacommunation of children.

Linhui Li used the half structure experiment in Shanghai, 80 3-6 years old children were selected in the play, two themes (each 20 minutes) were designed, to explore the metacommunication development characteristics and regulars of Chinese preschool children in cooperative pretend play, the study found that: verbal proportion of 4-5 years old children in cooperation pretend play has changed significantly; 3-6 years old children in cooperative pretend play in a large number of use of expression metacommunication; The use rate of implicit metacommunation is higher than that of explicit metacommunation. With the growth of age, the use rate of implicit metacommunation decreases slightly. During the play, children of all ages can accurately understand the verbal and non-verbal signals used by the other party for pretend, so that the communication between two children basically remains within the frame. In order from high to low, the formal usage rate is verbal metacommunication, verbal and non-verbal metacommunication, and non-verbal metacommunication. Children of different ages mostly use implicit verbal metacommunication, implicit verbal and non-verbal metacommunication, explicit verbal metacommunication, implicit nonverbal metacommunication, explicit verbal and non-verbal metacommunication. Among them, 3-year-old children used a lot of implicit nonverbal metacommunication. Children's speech discussion mainly focuses on the discussion of plans, objects, roles and actions, and the proportion of discussion on scenes and rules is $1 \%-5 \%$. [13]

Some researchers analyzed the significance of metacommunity in play and the basic characteristics of social viewpoints selections, and proposed the enlightenment of metacommunity theory on children's social viewpoint selection: focusing on enhancing peer interaction between children, cultivating children's self-control ability, developing their empathy ability and inference and integration ability. [14] It also analyzed the influence of metacommunication on play, especially symbolic play, role play and regular play. Metacommunication competence is the premise and guarantee of symbolic play; it affects children's emotional experience in role play and it is the basic requirement of the rule play continuity. [15] Some researchers through sorting out foreign researches on metacommunication, summaring the types of metacommunication, development characteristics and functions of metacommunication in children's play. [16]

\section{Object and Method of the Research}

\subsection{Research Object}

Following the sampling principal of convenience and pertinence, researchers take one kindergarten in Anning district of Lanzhou city as source place because of its large outside playground and a half day free play for children. The number of 60 children from elementary, middle and senior class is picked at random as objects of observation, among which 17 children from junior class with an average age of 39 months, 21 from middle class aged 52 months on average and 22 from senior class averaging 63 months.

\subsection{Research Method}

Observation is the major research method. Research workers conducted a 6-day pre-observation in advance aiming at selecting a target class from junior, middle and senior class respectively for formal observation. On top of this, researchers made a survey to children's partner relations of the target class through means of Peer Nominations so that post observation could give clear judgement for partner's focus in the initiation stage of the play. In the next stage, researchers make a 40-day formal observation in the kindergarten from 2:30 pm to 06:00 pm everyday. Using time sampling as method, researchers videoed the metacommunication signals used by children in the start-up stage of the pretend play by mobile phone and collected 118 play video footage in the end. Here in this paper metacommunication consists of verbal signals and non-verbal signals. Verbal signals mean languages including pure languages, language based on materials and language conveyed through body movements as well as changing voice composing pure changing voice, changing voice based on materials, changing voice expressed through body movements and laughter brought by changing voice. Non-verbal signals are body movements caused by materials, body movements as well as smile and grin to match the body behavior. To guarantee the efficiency of video material, everyday researchers undertake video transcription after they leave the kindergarten.

\subsubsection{The Method of Observation}

Since the appearance of pretend play has a certain 
randomness, this study adopts the event sampling method. September 18th. 2017 to October 13th. 2017 as the period of pre-observation, the purpose was select 3 classes as formal observation from 9 classes (each age group had 3 class), at the same time, familiar with the names of the children of each target class, the target class play activity time and the materials used. The official observation period is from October16th. 2017 to December 8th. 2017, a total of 40 days. Formal observation period to the selected class children pretend play launched metacommunication behavior and response behavior observation, researchers comes into the corresponding class every day, 18:00 to leave, for young children in the garden on the afternoon of the target class during the show all pretending to be a play and response behavior, after leaving the kindergarten in a timely manner transcribed. This study effectively observed a total of 36 hours, and collected 118 pretend play initiation fragments of 60 children, including 36 fragments of junior class children, 34 fragments of middle class children, and 48 fragments of senior class children.

\subsubsection{The Method of Measurement}

During the pre-observation, peer nomination (positive nomination) was used to investigate the peer relationship of children of the target classes, and to observe the peer orientation of children's metacomparative signals every time they initiate the pretend play, so as to make a quick judgment on the peer orientation of children's initiation of the pretend play during the observation and transcription during the formal observation period.

\section{Research Results and Analysis}

\subsection{The General Features of Metacommunication Signals in the Initiation of Pretend Play of Children}

To analyze collected 118 play video segments, researchers found children totally using 118 times metacommunication signals in the initiation of pretend play including 80 times verbal signals and 38 times non-verbal signals. And the top five metacommnunication signals used in the pretend play are pure language, body behavior, language based on material, language conveyed through body movements and pure changing voice according to the using frequency rank. Through this analysis results, we can see the usage of verbal signals are more than that of non-verbal signals.

The frequency of metacommunication signals used in the elementary, middle and senior class is 36, 34 and 48 times respectively. Of these metacommunication signals, body behavior is mainly used by children in elementary class and in middle class, it is language based on material at first and then laughter matched with changing voice appeared while children in senior class use pure language at most. These findings indicate that as children grow, the metacommunication signals they used gradually transferred from non-verbal signals to verbal signals.

\subsection{Feature of Metacommunication Signals in the Initiation pf Pretend Play of Children in the Different Activities}

\subsubsection{Range Activity}

i. Relying on certain material

Case one:

B1 takes a bar of plasticene saying to G1: "I'm gonna to make noddles". Hearing this, G1 learns as the B1 do to make noddles. Then B2 beside takes his/her plasticene and says: "I will make noddles too". "do it, I wanna do bread." said B1. “and I will do chocolate." said G1.

In this above case, child B1 knows plasticene being soft and easily bent to any models and initiates "noddle-making play" in a success. In the meantime, another two children with their plasticene at hand participate the play. Taking one thing to replace another thing is one of the features of pretend play. Material provided in the range activity helps to rouse children's action memory of one certain materials. Children could go into a fancy world by certain materials added with related role play game. [4]

ii. Exploring ability limited by material

When an activity of "operating one item leads some change of its location and shape" occurs, the play happens according to the study. [17] In other words, when children are able to perform some transformations based on the function and properties of materials, the symbolic meaning of the material could be seen. Children in the elementary class lack the experience to play with material, and need a process of exploring "what is this?" and thus in this stage the usage of metacommunication is dominated by simple stimulation. As children in the middle and senior class gradually grows abundant exploring experience, they can quickly do some changes in some degree in accordance with the properties and function of the material as well as initiate and propel the play matched with related verbal signals.

\subsection{Life Activity}

\subsubsection{Used Body Behavior}

Case two:

Children general sitting in the chairs wait for their parents after school. Here is a situation: B1 stretches his/her arms towards the way of corridor, then G1 wants to pass the way beside B1 but failed for B1's stop. And so G1 also stretches his/her one arm and says "swiping card". Next B1 puts down his/her arm and smiles slightly.

Children in life activity have a tendency using their body behavior to initiate pretend play toward others. In the case above, B1 applies the experience of taking bus collected from group activity to the pretend play and change the current life situation using body behavior. The pretend play can go ahead for the intention of play soon be recognized by G1.

\subsubsection{Impromptu Cases}

Case three:

After lunch, B1 standing beside the table looks around and suddenly he said by covering his one eye, "I am the one-eyed 
robber, this orchard is mine." And now G1 is placing the plate on the table while the B1 continues, "don't move or I will trigger the gun." "don't, please, don't do that, i don't have money." said G1 trembly.

R. K. Sawyer pointed that the pretend play initiated by children in the activity room is like the jazz performance, featuring the impromptu creativity. [26] In the case above, B1 impromptu play the role of robber sending metecommunication signals to his classmate matching his body behavior. At first, G1 could not go into the play, but with B1 further using verbal signals, G1 then makes response through verbal signals. In the end the play could go on for both of B1 and G1 are in the same frame of play.

\subsection{The Features of Metecommunication Signals of the Initiation of Pretend Play of Children Under Different of Peer Relation}

\subsubsection{Can Be recognized}

Case four:

In the constructive game area, B1 putting his matched material on the table moves it forward and makes sounds like "Wu...." in the meantime. B2 sitting beside rises up and tries to kick B1's material, imitating the sound of "Wu..." made by B1. They take around along the side of table round after round.

When children get familiar with each other, play initiator's implicit intention given through metecommunication signals will be soon recognized bu his/her peers and rouse response within the frame of play. Both B1 and B2 in the cases above are boys and often play together. And thus, when B1 in the help of changing voice matched with body behavior gives metecommunication signals, B2 recognizes B1's intention immediately, that is "driving the train". then he plays the role of train driver with B1 and helps himself to fit the play by voice and body behavior.

\subsubsection{Continuously Shift}

Case five:

In the constructive area, B2 holds up his works and repeats "Transformers, Transformers." right in this time, B1 hangs his U-shaped work in the ear. Seeing this, B2, putting his "Transformers" on the ear, says, "hello, B1 dad. This is teacher. We have no homework today." then G1 puts up his hand saying "yes, yes, is there anything else by teachers? I have just been to mall for lipstick." "G1 mother, children tomorrow can enjoy a day-off, so you don's need send your child to school." replied B2.

In the case above, B2 tries to emit play intention in the beginning but failed to rouse B1's response when he makes meaning transformation (Transformers) of material. Again B2 makes meaning transformation (telephone) to the material and rules the role of himself and peer to be the teacher and parent by using his body behavior. G1 responses to B2 with the evidence of his body behavior and verbal expression accepted the play frame set by B2 and joins the play. In this process, the first emitted metecommunication signals could not recognized by peers and play could not continue, B2 then gives material new meaning, adjusting the metacommunication signals and planning the play frame with play condition, rules and roles included. Then, due to both players know the play, consensus can be reached among them and the play can further move ahead.

\subsection{Unfamiliarity to Peer Relation}

\section{Repeatedly explanation}

Case six:

In constructive activity, G1 climbs in front of G2 and gives signs toward building block by mouth, stretching his arms in the meantime. G2 makes no response and G1 continues to give signs accompanied with the sound of "jia, jia". then G2 gives a pink building block to G1 and G1 holds it in his breast, grinning happily and pointing the building block in the distant. G2 don't have other response but slight body movement. G1 climbs to fetch the building block he pointed and says to G1, "let us build a house." G2 climbs to find more building block.

When children don not get familiar with each other, the intention of play initiator might not be recognized bu his/her peers so that the initiator needs to give more explicit signs like clear verbal hints or action demonstration and etc. In the case above, G1 tries to launch play by non-verbal signs in the very first place but failed then he/she uses words matched with body movement to make G2 understand his/her play intention.

Case seven:

In "hospital" area, G1 puts most of the "medical equipment" in front of himself. And G2 takes one of needles, hearing G1 said, "it is mine." and G1 wears echometer saying, "how old are you, baby?". "I am four years old." replied G2. G1 corrected him as "it should be the baby is four years old."

In the case above, teacher prefers to G1. G1 first claims his own to the play material by verbal announcement then makes settings to the play condition and role by changing voice matched body behavior like coughing or changed the tone of voice. Seeing from G2's reply, G2 don's real go into the role of "baby's parents" while G1's correct to him makes the play continue. According to W. A. Corsaro, mutual control is one of the core themes of children' peer culture. [18] When the desire of control is struggled with the relation between teachers and children themselves and with the status of groups, the disparity of identify caused by the strength of power would affect the way of how the play initiated and its final trend.

\section{Suggestion and Conclusion}

\subsection{Properly Place Regional Material}

In a word, metacommunication signals used by children in the regional activity tend to depend on specific material. Low-structured material for its uncertain properties and various playing ways is easy for children to attach special meaning by their free conduct. And thus, teachers should provide more this kind of material for children and besides should update the sorts of it to inspire children's exploring desire to launch new play. 


\subsection{Support Children's Spontaneous Communicative Activities}

Children are experiencing the process of symbolic acquisition starting the moment of born said by Li shanze and Li chuanying (two scholars in China) in 2007. [24] Metacommunication signals are exact an abstract communication based on the symbolic level and first appeared between parents and children then transferred to the peer interaction. In addition to explicit feature of the goods for goods by using specific material, children often involve in the play voluntarily with the help of facial expressions, body gestures and other impromptu symbols. During this process, the both sides in the play will recognize and make response to metacommunication signals and modulate their words and action, which helps to grow cognitive flexibility. In this aspect, teachers should back children's impromptu interaction activity and enlarge their interaction range to enhance mutual understanding by changing the order of seats and setting the rules of regional activities.

\subsection{Promote the Development of the Psychological Theory of Children in Junior Class}

Studies find the matecommunication signals used by children in the elementary class are mainly body movements and stays in simple imitation level, which related to the their psychological theory level. It has shown in the studies that children is not until the age of four could see from others and adopt different verbal expression or make proper response to peer's behavior. For this, teachers should encourage children take the initiative to launch the play to their peer by exploring the play itself or explicit words and facial expressions. In addition, interaction activities of children with different ages and drama play with related theme can help to enrich children's interpersonal cognition and promote the development of psychological theory.

Play mobilized the development of children's metacommunicatve ability, and vice versa. Kindergarten teachers need to focus on the changes of children's metacommunicative ability in the play and in the meantime promote their ability.

\section{References}

[1] G. Bateson. (2006). A Theory of play and fantasy. Cambridge: The mit press.

[2] Yan Liu. (2004). General theory of children's play. Beijing: Beijing normal university press, 133.

[3] Sheng HSI L (1994). Gender differences in initiation and maintenance of pretend play with Taiwanese children. Austin: The university of texas at Austin.
[4] C. Garvey. (1990). Play enlarged edition. Harvard University Press.

[5] Helen B. Schwartzman. (1978). Transformations: The Anthropology of Children's Play. New York: Plenum Press. 1978.

[6] Holly Lynne N. Giffin. (1982). The Metacommunicative Process in Collective Make-believe Play. Ph D. Dissertation, University of Colorado at Boulder. Abstract.

[7] L. Frost; S. C. Wortham; S. Reifel. translated by Ying Zhang, Xiaojuan Tang. (2011). Play and children's development. Jiangsu educational press, 125-126.

[8] Brenda-Joyce. Boyd (1991). Metacommunication in Young Children's Pretend Play: An Instrument Development Study. $\mathrm{PhD}$. Dissertation, The University of Georgia.

[9] Sheng-hsi Lin. (1994). Gender Differences in initiation and Maintenance of Prete-nd Play With Taiwanese Children. PhD. Dissertation, The University of Texas at Austin. 1994.

[10] Sheng-Hsi Lin (1994). Gender Differences in initiation and Maintenance of Pretend Play With Taiwanese Children. Ph D. Dissertation, The University of Texas at Austin, 27, 58.

[11] Sheng-Hsi Lin. (1994). Gender Differences in initiation and Maintenance of Pretend Play With Taiwanese Children. Ph D. Dissertation, The University of Texas at Austin, 213; 26.

[12] Anna-Beth Doyle, Jennifer Connolly. (1987). Negotiation and Enactment in Social Pretend Play: Relations to Social Acce-ptance and Social Cognition [C]. Ottawa, Ontario, Canada: Social Science and Humanities Rearch Council of Canada. Abstract.

[13] Linhui Li. (2008). The metecommunication development research of the cooperative play of children aged from 3-6 yearold. Paper of master's degree of East China Normal University.

[14] Yujiao Huang. (2013, Feb). The theory of metacommunication of play to the revelation children's social viewpoint selection. Journal of current preschool education.

[15] Xiuling $\mathrm{Xu}$, Shan Liu. (2015, Jan). The influence of metacommuncative ability to the children play. Journal of Education/Development. 2015. 01.

[16] Ziyu Meng. (2016, Dec). Types, characteristics and influences of metacommunication in children's play. Journal of Earlychildhood Education.

[17] W. A. Corsaro. (2016). translated by Lanyu Zhang. Sociology of childhood. Heilongjiang education press, 121-133.

[18] Shanze Li, Chuanying Li. (2007, Feb). The theory on symbolic value of the pretend play of children. Preschool Educational Research. 